\title{
A EDUCAÇÃo SEXUAL NA PERSPECTIVA DAS PROFESSORAS DO 5은 ANO DO ENSINO FUNDAMENTAL
}

\author{
Renata Geremias da Silva ${ }^{1}$ \\ Gislene Camargo ${ }^{2}$
}

\section{INTRODUÇÃO}

Esse artigo é resultado de uma pesquisa realizada para um trabalho de conclusão de curso. A escolha do tema em questão deu-se devido a um trabalho solicitado na $2^{\text {a }}$ fase do Curso de Pedagogia da UNESC, na disciplina de Psicologia do Desenvolvimento, na qual o grupo em que eu estava presente pesquisou e apresentou sobre o "Desenvolvimento da sexualidade segundo Freud".

Tal estudo me levou a pensar sobre a importância de o/a professor/a compreender a sexualidade, livre do preconceito, medos e falsas crenças. Sendo que para isso, é preciso que o/a mesmo/a compreenda a sua sexualidade e a de seus/suas alunos/as, para poder trabalhá-la em sala de aula, possibilitando uma vida mais saudável a si e aos/às educandos/as.

Outro fator determinante na escolha do tema se deu enquanto estagiária do Ensino Fundamental no ano de 2014, presenciei uma situação em que uma aluna do $1^{\circ}$ ano mostrou sua genitália a uma colega e a professora titular, bem como outras professoras da escola, ao saberem disso, escandalizaram-se, a ponto de as meninas serem proibidas de brincarem juntas. Essa situação me fez refletir sobre como algumas/alguns professoras/es estão despreparadas/os para lidar com a temática da sexualidade, fortalecendo-a como tabu.

Assim sendo, a pesquisa teve como problema a seguinte inquietação: "De que forma as/os professoras/es do $5^{\circ}$ ano trabalham a Educação Sexual com seus/suas alunos/as?". E como objetivo geral: "Analisar de que forma a Educação Sexual é trabalhada pelas/os professoras/es no $5^{\circ}$ ano do Ensino Fundamental".

\footnotetext{
${ }^{1}$ Universidade do Extremo Sul Catarinense - UNESC - renatageremiasds@hotmail.com

${ }^{2}$ Universidade do Extremo Sul Catarinense - UNESC - gislene@unesc.net
} 
Para a realização da presente pesquisa utilizou-se como instrumento de coleta de dados o questionário, que foi aplicado a 7 (sete) professoras (todas são do gênero feminino) que lecionam na cidade de Criciúma - SC, 4 (quatro) atuam em uma mesma escola e 3 (três) em outra.

Dentre os/as autores/as pesquisados/as pode-se destacar Freitas e Chagas (2013), Furlani (2011), Nunes (1996), Piletti, Rossato e Rossato (2014), Rabelo e Ferreira (2013), além dos documentos oficiais, como os PCN's (BRASIL, 1997), a PCSC (SANTA CATARINA, 1998) e a Proposta Curricular da Rede Municipal de Criciúma (CRICIÚMA, 2008).

\section{RECORTES HISTÓRICOS DE ABORDAGENS DE EDUCAÇÃO SEXUAL E SEUS REFLEXOS NA EDUCAÇÃO ESCOLAR}

Abordar a temática sexualidade não é tarefa fácil, pois essa, historicamente, é carregada de tabus e preconceitos que ainda hoje, são difíceis de desfazer. Se para a maioria dos adultos falar de sua própria sexualidade é algo constrangedor, discutir a sexualidade de crianças é ainda mais complicado, e muitas vezes, visto como inconveniente. Isso porque durante muito tempo, até o final do século XIX, de acordo com Priszkulnik (2004), a criança era vista como um ser puro, assexuado e inocente.

Foram as investigações de Sigmund Freud nos estudos das histéricas que o levaram à descoberta da sexualidade infantil, mostrando que a tese de que a sexualidade se constitui somente na puberdade, precisaria ser revista (KUPFER, 1997). Para melhor compreender o fato de que a criança assim como o adulto possui sexualidade, se faz necessário compreender antes, o conceito de sexualidade.

De acordo com Figueiró (2006 apud NOTA, 2013, p. 239) "a sexualidade é uma dimensão ontológica essencialmente humana, cujas significações e vivências são determinadas pela natureza, pelas subjectividades de cada ser humano e, sobretudo, pela cultura num processo histórico e dialéctico."

Dessa forma, a sexualidade é algo que nasce com o ser humano e vai se constituindo, obtendo significado, a partir das vivências do sujeito, tendo influência direta da cultura na qual o mesmo está inserido. Com isso, é 
importante que a escola tenha em seu currículo a Educação Sexual, sendo que poderão surgir diversas situações referentes à sexualidade dos/as alunos/as.

Freitas e Chagas (2013, p. 126), ao citarem alguns autores que falam sobre a Educação Sexual, dizem que:

\begin{abstract}
Werebe (1998), Nunes (1987), Guimarães (1995) e Figueiró (2001), dentre tantos outros/as autores/as que tratam desta temática, entendem que a ES se faz por meio da transmissão dos valores éticos, morais, religiosos e culturais relativos à vivência do sexo. Tudo o que é ensinado/transmitido às crianças e aos jovens sobre o que pode e o que 'não pode', o 'certo' e o 'errado', o que 'deve' e o que 'não deve' ser falado, pensado ou vivido em relação ao sexo, à percepção do corpo e dos papéis de gênero, é o que entendemos ser um trabalho de ES
\end{abstract}

A partir dessa afirmação, entende-se que a Educação Sexual envolve tudo o que o/a professor/a transmite/ensina aos seus/suas alunos/as sobre a sexualidade.

Nunes (1996) destaca que há quatro abordagens diferentes de Educação Sexual presentes nas escolas brasileiras, a abordagem médicobiologista, a abordagem terapêutico-descompressiva, a abordagem normativainstitucional; e a abordagem consumista e quantitativa pós-moderna.

Por considerar essas quatro abordagens contraditórias, Nunes (1996) propõe uma abordagem diferente, a abordagem emancipatória. Essa abordagem também é destaque no trabalho de Freitas e Chagas (2013, p. 129), ao afirmarem que "A ES intencional numa perspectiva emancipatória deve necessariamente rever criticamente a norma sexual hegemônica repressiva, vigente na nossa cultura para criticá-la/problematizá-la." É uma abordagem então crítica, que não reproduz as maneiras de encarar a sexualidade presentes em nossa sociedade.

No entendimento de Furlani (2011), além da abordagem emancipatória, há outras três abordagens que estão próximas do reconhecimento das diferenças de maneira positiva e benéfica, que são nomeadas por ela de abordagem dos direitos humanos, abordagem dos direitos sexuais e abordagem queer.

Assim, compreende-se que não há somente uma maneira de acontecer a Educação Sexual na escola, o que remete ao/à professor/a escolher e realizar aquela(s) que promova(m) o desenvolvimento integral de 
seus/suas alunos/as. Para tanto, se faz necessário haver profissionais capacitados para trabalhar a Educação Sexual.

Rabelo e Ferreira (2013), falam da importância de formar profissionais da educação que compreendam as questões de sexualidade, para que possam trabalhar a temática e para que ultrapassem seus próprios preconceitos. Também defendem uma formação que permita a reflexão dos/as professores/as sobre sua prática cotidiana, que façam com que os/as professores/as reinterpretem as concepções vindas de um contexto histórico que por muito tempo dominaram mitos, crenças e tabus, sendo capaz de desconstruí-los.

Já que, questões sobre a sexualidade estão presentes nas instituições de ensino e afloram nos mínimos detalhes da prática pedagógica (RABELO; FERREIRA, 2013). Ou seja, em muitos momentos, questões relativas à sexualidade emergem em sala de aula, se mostrando como uma oportunidade para professores/as e alunos/as de desmistificar e construir saberes. Entretanto, somente um/a profissional capacitado, com uma formação sólida, saberá aproveitar essa oportunidade.

\section{A LEGALIDADE DA EDUCAÇÃO SEXUAL NO ENSINO FUNDAMENTAL}

Sabendo da importância da prática da Educação Sexual nas escolas, cabe ressaltar que no Brasil não existe uma lei que a torne obrigatória. Porém, no ano de 1997 foi elaborado pelo Ministério da Educação os Parâmetros Curriculares Nacionais (PCN's), que trazem questões referentes à sexualidade como objeto de estudo nas instituições de ensino (RIBEIRO, 2013).

Esclarecendo o que dizem os PCN's, Rabelo e Ferreira (2013) afirmam que os mesmos referem-se à sexualidade como Tema Transversal, devendo ser trabalhada de forma integrada, contínua e sistemática, incorporada às áreas do conhecimento já existentes bem como ao trabalho educativo da escola.

Quando se referem ao trabalho com a temática da sexualidade na escola, os PCN's utilizam a nomenclatura Orientação Sexual, e não Educação Sexual, como é adotada na presente pesquisa. Os conteúdos de Orientação 
Sexual para os anos iniciais do Ensino Fundamental são divididos pelos PCN's em três blocos, são eles: Corpo: matriz da sexualidade; Relações de gênero; e Prevenção às Doenças Sexualmente Transmissíveis/Aids, que são flexíveis (BRASIL, 1997).

Além dos PCN's, temos mais outros dois documentos oficiais que abordam o trabalho com a sexualidade na escola, um a nível estadual, a PCSC (Proposta Curricular de Santa Catarina), e outro a nível municipal, a Proposta Curricular da Rede Municipal de Criciúma. Diferentemente dos PCN's que dividem os conteúdos a serem trabalhos em três blocos, a PCSC (SANTA CATARINA, 1998) aborda o trabalho com a Educação Sexual na infância e na adolescência. Já a Proposta Curricular de Criciúma (CRICIÚMA, 2008), discute questões pertinentes à sexualidade na disciplina de Ciências Naturais.

O livro "Educação Sexual na sala de aula" de Furlani (2011), também traz algumas possibilidades didáticas de Educação Sexual na Educação Infantil e Ensino Fundamental, com a sugestão de algumas atividades para iniciar a Educação Sexual, que devem ser intencionalmente planejadas e permitir a reflexão sobre a temática da sexualidade e sobre as identidades culturais que constituem os sujeitos, de modo a problematizar os preconceitos e promover uma sociedade igualitária.

Cabe ressaltar que como o foco da pesquisa é o trabalho de Educação Sexual no $5^{\circ}$ ano do Ensino Fundamental, faz-se necessário caracterizar esse/a aluno/a. De acordo com o artigo $2^{\circ}$ do ECA (Estatuto da Criança e do Adolescente), é considerada criança a pessoa até os 12 anos de idade incompletos (BRASIL, 1990). Dessa forma, considerando que a maioria dos/as alunos/as do $5^{\circ}$ ano possuem 10 anos de idade, pode-se afirmar que a turma é composta por alunos/as crianças.

Entende-se ainda que os/as alunos/as do $5^{\circ}$ ano do Ensino Fundamental estão vivenciando o período da latência, sendo que a mesma ocorre de acordo com Kahn (2013) dos 7 anos até a puberdade, e conforme Piletti, Rossato e Rossato (2014), uma de suas características, é a libido (energia sexual) voltada para outros fins, não sexual. Em relação à puberdade, na concepção da PCSC (SANTA CATARINA, 1998), ela é a primeira etapa da adolescência.

Compreendendo as características básicas dos/as alunos/as do $5^{\circ}$ 
ano do Ensino Fundamental é possível planejar a ação pedagógica em todos os aspectos, e não só no que diz respeito à temática da sexualidade, de maneira adequada, propiciando aprendizagens com significado(s).

A pesquisa teve caráter qualitativo e $\mathrm{o}$ instrumento de coleta de dados utilizado foi o questionário. $O$ que motivou a opção pelo $5^{\circ}$ ano do Ensino Fundamental foi a idade dos/as alunos/as, na qual a grande maioria das crianças possuem 10 anos, podendo estar em transição da infância para a adolescência (puberdade), período que ocorrem várias mudanças corporais, e as curiosidades sobre a sexualidade que podem acontecer nessa fase. Para assim, buscar descobrir como as/os professoras/es tratam essas questões e se possuem planejamento envolvendo a temática.

Desse modo, os sujeitos da pesquisa foram 7 (sete) professoras (todas são do gênero feminino) do $5^{\circ}$ ano do Ensino Fundamental, que trabalham em Criciúma - SC. Dentre todas as escolas do município, foram escolhidas duas escolas especificamente por serem próximas geograficamente da pesquisadora. Dessas duas escolas, foram pesquisadas todas as professoras do $5^{\circ}$ ano que lá lecionam, 4 (quatro) em uma escola e 3 (três) em outra.

Em relação à apresentação e análise de dados, as professoras serão identificadas como professora 1, professora 2, professora 3, professora 4, professora 5, professora 6 e professora 7. Para facilitar a comparação dos dados, as respostas obtidas foram agrupadas em categorias. Cada categoria possui dados referentes à sua temática. Assim, têm-se as seguintes categorias de análise: "A perspectiva das professoras sobre sexualidade e Educação Sexual", "O trabalho de Educação Sexual desenvolvido pelas professoras" e "Educação Sexual: uma proposta a ser desenvolvida".

\section{A PERSPECTIVA DAS PROFESSORAS SOBRE SEXUALIDADE E EDUCAÇÃO SEXUAL}

Quando questionadas sobre o que entendem por sexualidade, a maioria das professoras limitou-se somente a um aspecto da sexualidade humana, como corpo. A partir do aporte teórico dessa pesquisa, pode-se considerar esse conceito equivocado. 
Porém, a professora 6 , além de responder que sexualidade é conhecer o corpo, ela também afirmou, assim como a professora 3 , que a sexualidade é algo que faz parte do ser humano, o que também é defendido por Figueiró (2006 apud NOTA, 2013), ao dizer que a sexualidade é uma dimensão humana. Portanto, a professora 6 que equivocou-se numa afirmativa, foi coerente em outra.

Quando indagadas sobre o que entendem por Educação Sexual, a maioria das pesquisadas respondeu que é o ensino da reprodução humana. Esse entendimento da Educação Sexual voltado para a reprodução humana pertence aos pressupostos da abordagem médico-biologista, que segundo Nunes (1996, p. 140) faz,

[...] com que a sexualidade seja vista como uma mera força propulsora da procriação. Esta interpretação encontra defensores nas estruturas de articulação entre as Ciências Naturais e alguns setores da Psicologia Comportamental. [...] Nesta visão, estudar a sexualidade humana demandaria compreender o funcionamento dos aparelhos reprodutivos na evolução animal [...].

Abordagem essa que é criticada pelo autor por reduzir a sexualidade ao ato de perpetuação da espécie (NUNES, 1996).

Sobre como os/as alunos/as do $5^{\circ}$ ano são nomeados por sua professora, as professoras 2, 3 e 7 consideram seus/suas alunos/as crianças. De fato, como já afirmado, já que a maioria dos/as alunos/as do 5ํao do Ensino Fundamental possuem 10 anos, pode-se considerá-los/as crianças, sendo que o ECA estabelece a condição de criança para quem possui até 12 anos incompletos (BRASIL, 1990).

Já as professoras 1, 4 e 6 trouxeram a questão da puberdade, assim como trazem Piletti, Rossato e Rossato (2014). Somente a professora 5 abordou em sua resposta os dois termos, criança e puberdade.

Todas as pesquisadas afirmaram que conhecem como ocorre o desenvolvimento da sexualidade com os/as alunos/as do $5^{\circ}$ ano, sem falar do período da latência abordado por Kahn (2013) e por Piletti, Rossato e Rossato (2014).

Quanto ao posicionamento das professoras quando algum/a aluno/a Ihe questiona algo que diz respeito à sexualidade, todas as professoras 
afirmaram ter tranquilidade ao lidar com esses questionamentos, nenhuma professora apresentou alguma dificuldade nessa situação.

Com isso, é possível observar que em relação à temática da sexualidade bem como ao trabalho de Educação Sexual, há falta de compreensão pela maioria das professoras pesquisadas, pois as mesmas limitam-se somente a um aspecto da sexualidade, como corpo e reprodução, esquecendo-se das demais dimensões da sexualidade humana, que são trazidas pela PCSC (SANTA CATARINA, 1998), como a histórica e a cultural.

\section{O tRABalho de educaçÃo sexual desenVolvido PELAS PROFESSORAS}

Quando indagadas se consideram importante trabalhar a Educação Sexual com seus/suas alunos/as, a maioria das professoras respondeu que sim, e quando questionadas se planejam as aulas de Educação Sexual, somente as professoras 4, 5 e 6 responderam que sim. Os PCN's (BRASIL, 1997), a PCSC (SANTA CATARINA, 1998) e Furlani (2011) concordam de que há necessidade de planejamento para as aulas de Educação Sexual.

Se a resposta fosse positiva quanto ao planejamento, as professoras deveriam dizer quais metodologias utilizam. As mesmas citaram um recurso, e não metodologia, em comum. Disseram usar vídeos.

Ao serem indagadas se a escola em que trabalham possui em seu currículo uma proposta para trabalhar a Educação Sexual e se há algum conteúdo envolvendo a temática no livro/apostila utilizada, as professoras 1, 2, 3 e 6 afirmaram que no currículo da escola não há proposta para se trabalhar a Educação Sexual. Quanto a isso, sabe-se que por meio dos documentos oficiais (PCN's, PCSC e Proposta de Criciúma) temos uma proposta de inserção da Educação Sexual no currículo escolar. Dessas professoras, somente as professoras 1 e 6 disseram que no livro/material utilizado pela escola, mais especificamente no de ciências, há conteúdos referentes à Educação Sexual.

As professoras 4 e 5 não responderam se no currículo da escola em que trabalham há a Educação Sexual, responderam somente que trabalham o sistema reprodutor, entre outros conteúdos que são voltados para a área das 
Ciências Naturais.

A partir das respostas obtidas pelas professoras nessa categoria, pode-se afirmar que o trabalho desenvolvido pelas mesmas não contempla todas as dimensões da sexualidade, como a cultural, política, afetiva e outras, predominando sobre essas a dimensão biológica. Além disso, de acordo com as respostas, o trabalho de Educação Sexual das professoras não permite a reflexão, possibilitando que os/as alunos/as sejam críticos frente ao conhecimento sobre Educação Sexual, sendo que as mesmas não possuem um conceito esclarecido sobre metodologia.

Após a análise dessa categoria, também é possível pensar sobre como muitas escolas não levam a Educação Sexual a sério, sendo que podese perceber a ausência dessa área do conhecimento no currículo das escolas de acordo com a resposta da maioria das pesquisadas. É de suma importância que todos/as os/as envolvidos/as no ambiente escolar compreendam a necessidade de acontecer a Educação Sexual, já que é direito de todo/a aluno/a fazer parte de uma educação de qualidade.

\section{EDUCAÇÃO SEXUAL: UMA PROPOSTA A SER DESENVOLVIDA}

Já se sabe que as escolas não possuem a Educação Sexual em seu currículo, e ao serem questionadas se a escola em que trabalham possibilita cursos de formação continuada sobre Educação Sexual, a maioria das professoras disse que não. A professora 3 ainda justificou afirmando que "Infelizmente a demanda pedagógica prioriza outras informações específicas." Reconhecendo, assim como Rabelo e Ferreira (2013), que as formações continuadas nessa área são pouquíssimas ou até inexistentes.

Quando questionadas se já participaram de algum curso que abordou a temática da Educação Sexual, a maioria respondeu que não. Mas, ainda assim, quando indagadas se sentem preparadas para trabalhar a Educação Sexual, a maioria das professoras afirmou que sim.

Com isso, justifica-se o título dessa categoria de análise, que a Educação Sexual é uma proposta a ser desenvolvida, sendo que muitas escolas são deficientes em relação a esse trabalho e muitos/as professores/as, assim como as professoras pesquisadas, afirmam estar preparados/as para 
trabalhar a temática, mas a trabalham de forma limitada ou a partir de um conceito que contemple pouco entendimento sobre sexualidade e Educação Sexual, e a maioria não participou de formações/cursos sobre o tema.

\section{CONCLUSÃO}

Ainda que existam autores/as que concebem a sexualidade como dimensão humana, destacando a importância de um trabalho competente de Educação Sexual, há professores/as que não possuem esse entendimento, nem um conhecimento coerente sobre como a sexualidade se desenvolve com seus/suas alunos/as, conforme mostrado por meio da presente pesquisa realizada com 7 (sete) professoras que lecionam no $5^{\circ}$ ano do Ensino Fundamental.

A maioria apresenta uma concepção voltada ao corpo e à reprodução, não considerando as demais dimensões que constituem a sexualidade humana, o que resulta num trabalho de Educação Sexual que não permite aos/às alunos/as conhecerem tudo o que constituí a sexualidade, inclusive como foi encarada historicamente e os muitos preconceitos, medos, crenças e tabus que a permeiam, como também os muitos movimentos que lutaram contra os mesmos, possibilitando a reflexão e desenvolvendo a autonomia. Além disso, muitos/as professores/as confundem metodologia de ensino com recursos.

O que mais agrava a situação é a ausência da Educação Sexual no currículo das escolas das pesquisadas (considerando a maioria das respostas), que por vezes pode reforçar a ideia de que tratar do assunto não é necessário e muito menos, importante.

Todas as professoras disseram reagir bem, com tranquilidade, em situações que envolvem a sexualidade de seus/suas alunos/as. Porém, a indagação que fica é como esse trabalho é possível se os conceitos/concepções apresentados não dão conta de suprir as demais curiosidades que possam emergir no $5^{\circ}$ ano?

Diante disso, pode-se afirmar que os objetivos traçados para a presente pesquisa foram atingidos. São várias as abordagens de Educação Sexual, como mostrado no referencial teórico, e nenhuma das professoras 
pesquisadas as citaram. Talvez, por desconhecimento. O que reflete num trabalho limitado de Educação Sexual.

Atribui-se genericamente que uma parcela da responsabilidade seja dos cursos de formação de professores/as que não abordam a temática (o que seria um interessante objeto para futuras pesquisas!), mas os documentos e as obras que tratam do assunto estão disponíveis a qualquer professor/a que reconheça a importância e necessidade de um trabalho efetivo de Educação Sexual. Nossos/as alunos/as (não só do 5aa) estão aí, presentes em nossas salas de aula com muitas dúvidas e vontade de discutir esse tema que atrai interesse, precisando da atenção de um/a professor/a que oportunize troca e construção de conhecimentos por meio de aulas intencionalmente planejadas.

\section{REFERÊNCIAS}

BRASIL. Lei no 8.069, de 13 de julho de 1990. Estatuto da Criança e do Adolescente. Brasília,1990. Disponível em: <http://www.planalto.gov.br/ccivil_03/Leis/L8069.htm> Acesso em: 19 set. 2015.

BRASIL, Secretaria de Educação Fundamental. Parâmetros Curriculares Nacionais: apresentação dos temas transversais, ética. Brasília: MEC/SEF, 1997. Disponível em: < http://portal.mec.gov.br/seb/arquivos/pdf/livro081.pdf> Acesso em: 24 ago. 2015.

BRASIL, Secretaria de Educação Fundamental. Parâmetros Curriculares Nacionais: Orientação Sexual. Brasília: MEC/SEF, 1997. Disponível em: < http://portal.mec.gov.br/seb/arquivos/pdf/livro102.pdf> Acesso em: 24 ago. 2015.

CRICIÚMA, Secretaria Municipal de Educação. Proposta Curricular da Rede Municipal de Criciúma: currículo para a diversidade: sentidos e práticas. Criciúma, SC: Secretaria Municipal de Educação, 2008.

FREITAS, Dilma Lucy de; CHAGAS, Isabel. Educação sexual em Portugal: a formação de professores como caminho. Um relato de experiências. In: RABELO, Amanda Oliveira; PEREIRA, Graziela Raupp; REIS, Maria Amélia de Souza (Orgs). Formação docente em gênero e sexualidade: entrelaçando teorias, políticas e práticas. Petrópolis, RJ: De Petrus et Alii; Rio de Janeiro: FAPERJ, 2013. p. 123-142. 
FURLANI, Jimena. Educação sexual na sala de aula: relações de gênero, orientação sexual e igualdade numa proposta de respeito ás diferenças. Belo Horizonte: Autêntica, 2011.

KAHN, Michael. Freud básico: pensamentos psicanalíticos para o século XXI. Tradução de Luiz Paulo Guanabara. Rio de Janeiro: BestBolso, 2013.

KUPFER, Maria Cristina Machado. Freud e a educação: o mestre do impossível. 3. ed. São Paulo: Scipione, 1997.

NOTA, Juvêncio Manuel. Reflectindo sobre a formação de professores de biologia em sexualidade e educação sexual na Universidade Pedagógica de Moçambique. In: RABELO, Amanda Oliveira; PEREIRA, Graziela Raupp; REIS, Maria Amélia de Souza (Orgs). Formação docente em gênero e sexualidade: entrelaçando teorias, políticas e práticas. Petrópolis, RJ: De Petrus et Alii; Rio de Janeiro: FAPERJ, 2013. p. 237-256.

NUNES, César Apareciddo. Filosofia, sexualidade e educação: as relações entre os pressupostos ético-sociais e histórico-culturais presentes nas abordagens institucionais sobre a educação sexual escolar. 1996. 319 f. Tese (Doutorado em Educação) - Universidade Estadual de Campinas, Campinas. Disponível em: < file://C:/Users/usuario/Downloads/NunesCesarApareciddo\%20(2).pdf > Acesso em: 20 jul 2015.

PILETTI, Nelson; ROSSATO, Solange Marques; ROSSATTO, Geovanio. Psicologia do desenvolvimento. São Paulo: Contexto, 2014.

PRISZKULNIK, Léia. A criança sob a ótica da Psicanálise: algumas considerações. Revista de Psicologia da Vetor Editora, São Paulo, v. 5, n. 1, p.72-77, jun. 2004. Disponível em: < http://pepsic.bvsalud.org/pdf/psic/v5n1/v5n1a09.pdf> Acesso em: 15 jul. 2015.

RABELO, Amanda Oliveira; FERREIRA, António Gomes. Formação docente em gênero e sexualidade: entre semelhanças e diferenças luso-brasileiras. In: RABELO, Amanda Oliveira; PEREIRA, Graziela Raupp; REIS, Maria Amélia de Souza (Orgs). Formação docente em gênero e sexualidade: entrelaçando teorias, políticas e práticas. Petrópolis, RJ: De Petrus et Alii; Rio de Janeiro: FAPERJ, 2013. p. 25-73. 
RIBEIRO, Paulo Rennes Marçal. A educação sexual na formação de professores: sexualidade, gênero e diversidade enquanto elementos para uma cidadania ativa. In: RABELO, Amanda Oliveira; PEREIRA, Graziela Raupp; REIS, Maria Amélia de Souza (Orgs). Formação docente em gênero e sexualidade: entrelaçando teorias, políticas e práticas. Petrópolis, RJ: De Petrus et Alii; Rio de Janeiro: FAPERJ, 2013. p. 7-15.

SANTA CATARINA. Secretaria de Estado da Educação e do Desporto. Proposta curricular de Santa Catarina. Educação Infantil, Ensino Fundamental e Médio: Temas Multidisciplinares. Florianópolis: COGEN, 1998. Disponível em: < file://C:/Users/usuario/Downloads/PC_Temas_Multidisciplinares\%20(2).pdf> Acesso em: 30 ago. 2015. 